\title{
Erratum to: Hydrogen sulfide induces heme oxygenase-1 in human kidney cells
}

\author{
Eliana D'Araio • Nicholas Shaw • Ann Millward • \\ Andrew Demaine $\cdot$ Matt Whiteman • \\ Andrea Hodgkinson
}

Published online: 14 August 2014

(C) Springer-Verlag Italia 2014

Erratum to: Acta Diabetol (2014) 51:155-157

DOI 10.1007/s00592-013-0501-y

Unfortunately, in the print and online version of article, the compound "GYY4134" was published incorrectly. The "GYY4134" compound should be replaced by "GYY4137" throughout the article.

Further, in "Methods", the concentration of AP39 was incorrectly published as $10 \mathrm{mM}$ and the correct concentration of AP39 is 10 nanoM.

The online version of the original article can be found under doi:10.1007/s00592-013-0501-y.

E. D'Araio · N. Shaw · A. Millward · A. Demaine .

A. Hodgkinson $(\square)$

Department of Molecular Medicine, Institute of Translational and Stratified Medicine, Plymouth University Peninsula Schools of Medicine and Dentistry, John Bull Building, Research Way, Plymouth PL6 8BU, England, UK

e-mail: ahodgkinson@pms.ac.uk

M. Whiteman

University of Exeter Medical School, University of Exeter,

St Luke's Campus, Magdalen Road, Exeter EX1 2LU,

England, UK 